\title{
PREDICTION OF STEM VOLUME OF ALSTONIA MACROPHYLLA GROWING AS EVEN-AGED MONOCULTURES USING DIAMETER AT BREAST HEIGHT AND TOTAL HEIGHT
}

\author{
S.M.C.U.P. Subasinghe \\ Department of Forestry and Environmental Science, University of Sri Jayewardenepura, Sri Lanka \\ Email: upul.forestry@gmail.com, Tel: +947 14450339, Fax: +941 2802914
}

\begin{abstract}
A growth model to predict the stem volume of Alstonia macrophylla was constructed in this study using data collected from 23 plantations from Galle, Matara, Ratnapura and Kalutara districts. Trees own variables were mainly used as explanatory variables in this study and in addition, site quality indices were also tested. At the preliminary analysis, two different site quality types were identified for the selected plantations. Therefore, first, each site quality data set was separately fitted to the theoretical models developed in this study. The selected models indicated a high modelling efficiency and a negligible bias. Although the possibility of using a common model for both site types was tested, results proved that it was not possible. Therefore it was decided to recommend two models (same structure with different sets of statistical parameters) for two site types for the field use with the help of a given guideline to identify the plantations grown in two site types.
\end{abstract}

Key words: Alstonia macrophylla, Volume estimation, Growth modelling

\section{INTRODUCTION}

Alstonia macrophylla Wall ex. G. Don belongs to family Apocynaceae is an introduced species to Sri Lanka from Malaysia. It has a fast growth rate and a very high adaptability to different soil types in the wet zone of Sri Lanka.

A. macrophylla timber is not durable although it produces dense wood. Due to this reason, this species is classified as Class III timber by the State Timber Corporation. Therefore the timber is recommended for moderate construction, common furniture and wall panelling. Other than that, it can be used as a raw material in manufacturing industries such as toys, drawing board, match sticks, veneer in ply wood manufacturing and packing boxes and lattices.

Since 1950s man-made forest plantations were highly promoted by the Forest Department in Sri Lanka to reduce the pressure on the existing natural forests and thereby to conserve the valuable biodiversity. Although the species such as teak, eucalypt, pine and mahogany were the popular species at the time of plantation establishment in large scale, recently Alstonia macrophylla also became popular due to the ease of establishment and the fast growth rate. At present it has been widely planted in Galle, Kalutara, Matara and Ratnapura districts by the Forest Department and also, a significant amount has been established by private companies (especially tea companies in their fallow lands). A. macrophylla is preferably grown in wet zone in Sri Lanka not only as plantations, but also as avenues, blocks or individuals in homegardens.

Modelling is especially important for species of widespread commercial use, both to understand growth and development of the species and to make better management decisions aimed at increasing productivity (Fernandez and Norero, 2006). Moreover, accurate growth and yield predictions of trees and forests are important requirements for facilitating sustainable management of forest resources.

In forest growth modelling, it is common to find both construction of new mathematical equations (e.g. Boisvenue et al., 2004; Fontes et al., 2003; Wang et al., 2005) as growth 
models or development of existing mathematical equations further to achieve more realistic predictions. Among the already available mathematical functions which have been used to develop growth or yield models in the past, Bertalanffy (1957), Lundqvist-Korf (1939) and Schumacher (1939) functions are most common (e.g. Adame et al., 2008; Palahi et al., 2004; Rammig et al., 2007; Salas and Garcia, 2006; Sanchez-Gonzales et al., 2005). The new models were mostly constructed by using assumptions on the relationships between response variable and candidate explanatory variables. In latter stages, those relationships were mathematically tested to obtain the statistical parameters which determine the magnitude and the direction of the relationships.

In commercial forestry, the important management decisions on different activities such as fertilizing, thinning and harvesting are taken long before the trees achieve the required end dimensions. Plantation age is therefore commonly considered as the first input parameter to predict the important tree growth variables such as diameter, height, volume etc. It is therefore important to be able to make predictions of required tree variables from age, so that the change of growth with time can be readily determined.

The objectives of the present study are (i) to classify the sites of the monocultures of $A$. macrophylla using top height related indices; and (ii) to construct precise mathematical growth models to predict the total volume.

\section{METHODOLOGY}

For the present study, four districts (i.e., Galle, Kalutara, Ratnapura and Matara) where A. macrophylla are commonly grown were selected. Both the government and private sector has established a considerable amount of this species in those areas. The necessary data were collected from even-aged plantations in these four districts. The details of the selected plantations and the individual blocks are given in Table 2.1.

\subsection{MEASUREMENTS TAKEN}

The age of the plantations were taken from the plantations records obtained from the Forest Department and the private owners. Sample size was 0.02 ha and the shape was circular. The number of samples measured in each plantation varied depending on the extent and the growth variation. Diameter at breast height $(\mathrm{dbh})$ and total height were measured as primary measurements. The stem volume of the standing trees are not possible to measure directly and therefore it was estimated from diameter and height of stem sections by using the following method.

The stem was divided into a few sections and the bottom diameter, top diameter and the middle diameter of each section was carefully measured using a penta-prism calliper. The length of each section was measured by a Blume-Leiss altimeter. Then the volume of each section was determined by the Newton's formula. The final part of the stem was assumed as a cone and the volume of the total tree stem was calculated by adding section volumes to the volume of the final part.

\subsection{SITE INDEX}

One of the main objectives of this study was to classify the sites of A. macrophylla plantations based on the growth performance. For this reason, it was decided to use an index which was developed by using top height and the age of the plantations as shown in the equation 2.1.

$$
\text { site index }(\mathrm{SI})=\text { top height / plantation age }
$$

Top height is the average height of the 100 thickest trees per ha. It has been widely accepted as a parameter, which is independent from the stand density. Therefore it is a good indicator of 
the quality of the site (Philip, 1994; Subasinghe 1998). However, it was not possible to use only top height as an indicator because it varies due to the age of the trees. As a solution to the above problem, a site index was developed by dividing the top height from the age of the plantation. Site indices were calculated for each sample plot in each plantation and the differences of those indices were determined by one-way ANOVA.

Table 2.1: Plantations measured for the present study (numbers in the brackets show the location in the map given in figure 3.1.

\begin{tabular}{|c|c|c|c|c|c|}
\hline District & Plantation & Code & $\begin{array}{c}\text { Age at } \\
\text { Measurement }\end{array}$ & $\begin{array}{c}\text { Mean dbh } \\
(\mathrm{cm})\end{array}$ & $\begin{array}{c}\text { Mean } \\
\text { height (m) }\end{array}$ \\
\hline \multirow[t]{5}{*}{ Galle } & Imaduwa & IM & 19 & 23.0 & 19.0 \\
\hline & Pituwalgoda & PG & 18 & 30.5 & 25.0 \\
\hline & Walambagala & WG & 20 & 37.9 & 27.8 \\
\hline & Wattehena I & WHI & 18 & 27.8 & 22.9 \\
\hline & Wattehena II & WHII & 18 & 30.8 & 22.6 \\
\hline \multirow[t]{8}{*}{ Kalutara } & Anguluwatota I & ATI & 18 & 17.5 & 21.1 \\
\hline & Anguluwatota II & ATII & 18 & 21.1 & 22.0 \\
\hline & Lihiniyawa & LY & 20 & 39.4 & 29.6 \\
\hline & Mellakanda & MK & 22 & 44.1 & 28.4 \\
\hline & Pelawatte & PW & 13 & 15.0 & 19.4 \\
\hline & Walallawita & WW & 22 & 36.4 & 29.8 \\
\hline & Yagirala I & YGI & 16 & 24.9 & 25.9 \\
\hline & Yagirala II & YGII & 16 & 21.9 & 22.8 \\
\hline \multirow[t]{5}{*}{ Matara } & Deniyaya & DY & 08 & 13.3 & 17.3 \\
\hline & Diyadawa & DD & 07 & 17.3 & 21.6 \\
\hline & Indola & ID & 05 & 09.2 & 12.8 \\
\hline & Keeripitiya & KP & 08 & 11.2 & 14.6 \\
\hline & Kotapola & KT & 10 & 14.2 & 18.2 \\
\hline \multirow[t]{5}{*}{ Ratnapura } & Denawaka & DW & 09 & 14.4 & 09.1 \\
\hline & Endana & ED & 10 & 12.4 & 16.9 \\
\hline & Kalawana & KW & 17 & 26.1 & 22.8 \\
\hline & Kuruwita & KU & 16 & 20.3 & 19.3 \\
\hline & Wellandura & WR & 08 & 11.4 & 09.6 \\
\hline
\end{tabular}

\subsection{MODEL CONSTRUCTION}

In order to construct the volume prediction model, the equation used to calculate the stem form factor (equation 2.2) was modified as described below.

$$
\begin{array}{rl}
v_{i}=g_{i}^{*} h_{i} * & f f_{i} \\
\text { where: } \quad g_{i} & =\text { basal area of the } i \text { th tree, } \mathrm{m}^{2} \\
f f_{i} & =\text { form factor of the } i \text { th tree } \\
h_{i} & =\text { total height of the } i \text { th tree, } \mathrm{m} \\
v_{i} & =\text { total tree volume of the } i \text { th tree, } \mathrm{m}^{3}
\end{array}
$$

(Philip, 1994)

Due to the fact that form factor varies with site variation, stand density, growth of crown and competition from the neighbouring trees (Avery and Burkhart, 1994; Philip, 1994), it was tried to replace by using some other variables mentioned above which are easily measurable. It was 
assumed that the competition is determined by the trees own parameters, number of trees growing in a unit area and quality of the site. Therefore the above equation was re-arranged as given below.

$$
\mathrm{v}=f(g, h, a, s, N, \text { crown depth })
$$

In addition to that, it was also decided to test the common logarithmic volume prediction model (equation 2.4) for the prediction of volume of the selected species.

$$
\log v=a+b_{1} \log d b h+b_{2} \log h
$$

(Source: Avery and Burkhart, 1994; Philip, 1994)

Then the data were fitted to the basic two model structures separately for separate site types. In addition to the un-transformed variables, four transformations (i.e., logarithmic, square, square root and reciprocal) were also used to construct the best model.

\subsection{MODEL EVALUATION AND VALIDATION}

The constructed models should be compatible with the biological reality. The models did not fulfil this requirement were removed from further analysis. In order to compare the performance of the constructed different models for the same purpose, both qualitative tests (distribution of the standard residuals) and the quantitative tests (average model bias, mean absolute difference and modelling efficiency) were used.

Following the work of Soares et al. (1995) and Vanclay (1994), 25\% of the sample plots were reserved before fitting the models to data. The reserved data were not used for the model construction but used to examine the validity of the models with independent data. For this task, the models were fitted to the reserved data and the distribution of normal residuals was examined with the fitted values.

\subsection{TESTING FOR COMMON PARAMETERS}

In order to eliminate the problem of using different models for different site types, it was tried to make a common volume prediction model for all site types. For this reason, new sets of parameters were estimated after pooling all data. Using newly estimated common parameters, the models were then fitted to each site type separately and normal residuals were calculated. Then the significance of these residuals calculated for each site type was tested using one-way ANOVA having the Null hypothesis that there is no significance difference between the residuals of different site types.

Even all the residuals are negatively or positively biased for all site types, they might still be statistically non-significant when the ANOVA test is applied. Therefore if the Null hypothesis was accepted, it was decided to plot the normal residuals against the fitted values of that common model to observe the visual bias.

\section{RESULTS}

According to the site classification, it was possible to identify two significantly different site classes as given in table 3.1. It was important to notice that all Class I sites are located in Matara district. Two other plantations of Matara district, i.e., Keeripitiya and Kotapola also showed the site quality closer to Class I.

Endana, Keeripitiya and Kotapola plantations indicated slightly different behaviour from the rest of the plantations in site Class II, those were, however, placed in the same class to reduce 
the complexity. From this point, it was decided to construct separate models for each site class until the possibility of using common models were tested at the end.

Table 3.1:

Proceedings of the 15 th International Forestry and Environment Symposium, 26-27 November 2010.

Published by Department of Forestry and Environmental Science, University of Sri Jayewardenepura, Sri Lanka. 


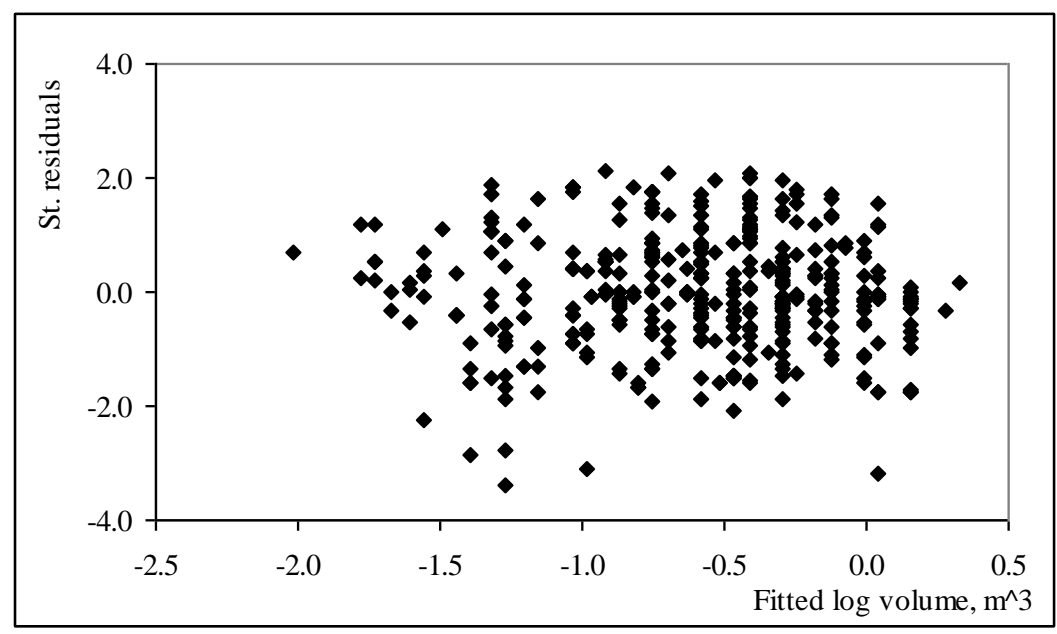

Figure 3.1: $\quad$ Standard residual distribution of the volume prediction model 3.1 (site Class II)

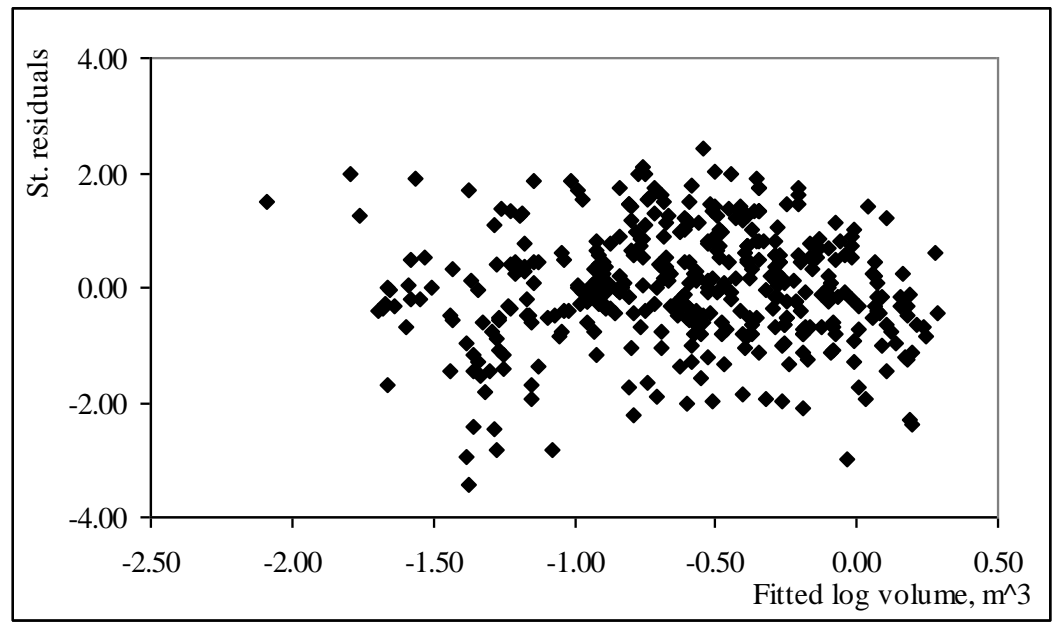

Figure 3.2: $\quad$ Standard residual distribution of the volume model 3.2 (site Class II).

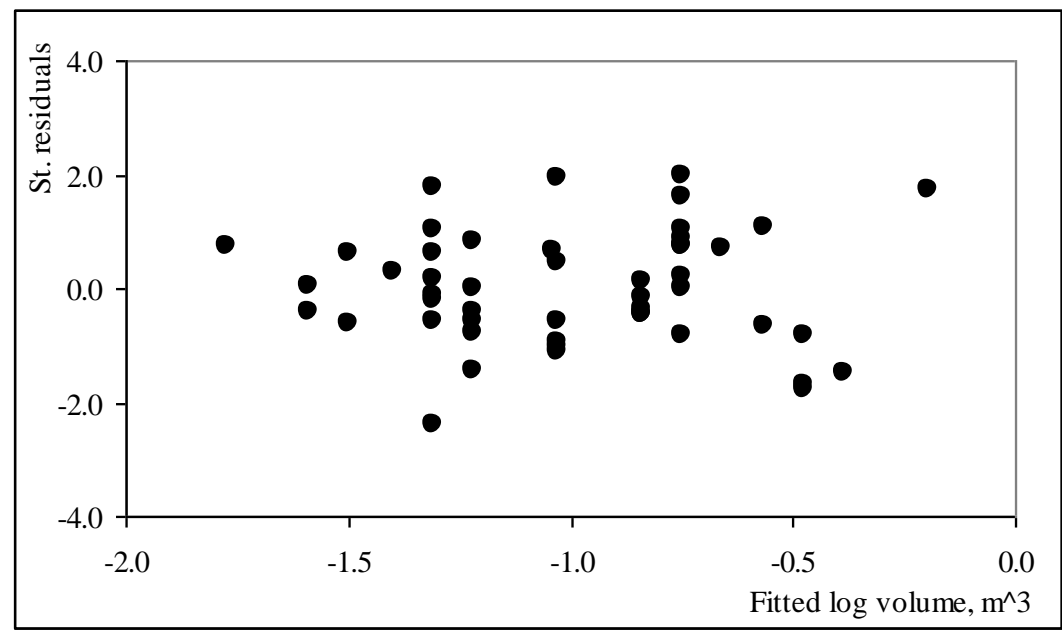

Figure 3.3: $\quad$ Standard residual distribution of the volume model 3.3 (site Class I). 
The selected logarithmic models (model 3.1 for the Class II and model 3.3 for the Class I) for the prediction of total stem volume of A. macrophylla grown as plantations for both site Classes indicated very high performances. This was proven when the quantitative evaluation of the model performance was conducted (Table 3.3).

Table 3.3: $\quad$ Results of the quantitative evaluation of the two selected models.

\begin{tabular}{lcc}
\hline Test & Site Class I & Site Class II \\
\hline Average model bias & -0.01 & 0.00 \\
Mean absolute difference & 0.03 & 0.09 \\
Modelling efficiency & 82.15 & 84.15 \\
\hline
\end{tabular}

\subsection{VALIDATION OF THE MODELS CONSTRUCTED FOR SITE CLASS II}

Figure 3.4 shows the results of the validation tests for the models constructed for site Class I for the present study.

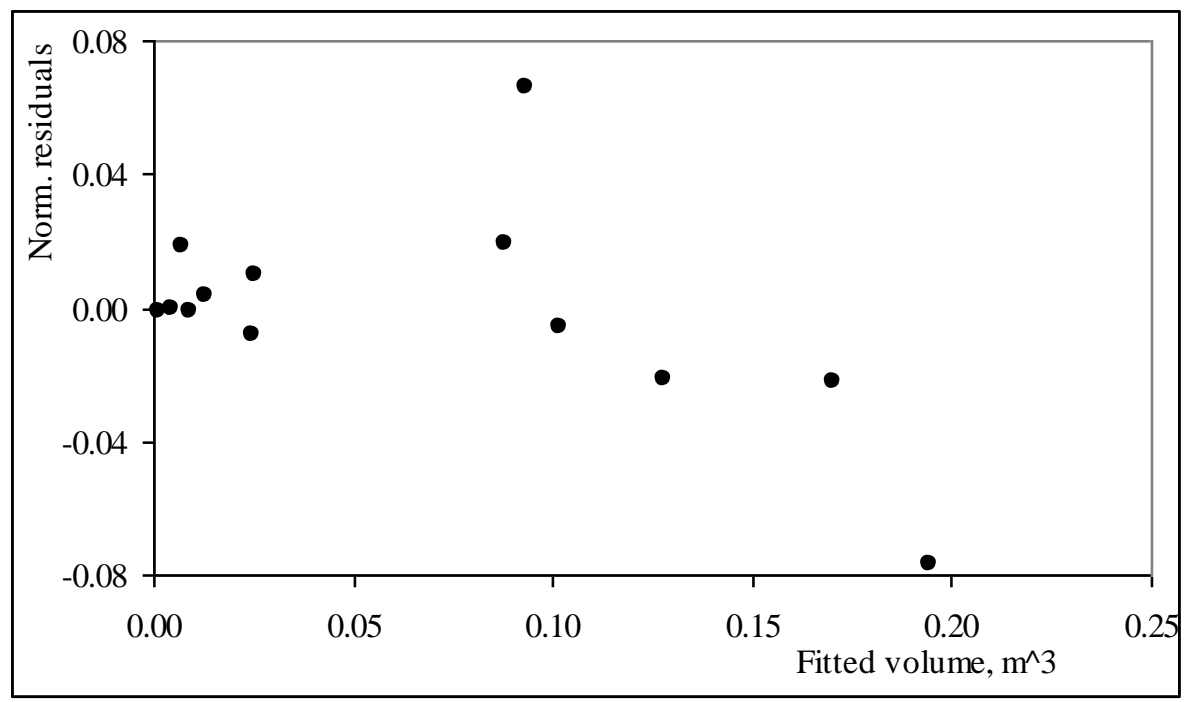

Figure 3.4: Results of the validation with independent data for Class I sites.

\subsection{TESTING FOR THE COMMON MODELS FOR ALL THE SITE TYPES}

For this reason, the methodology described in the Section 3.4 was followed. However, the results of one-way ANOVA test produced significant results proving that it was not possible to use a volume prediction model with common parameters for both site types. Therefore finally it was decided to use separate models for separate site types in this study.

\section{DISCUSSION}

Two major types of models were tested in this study. For the first type, a combined variable was used (basal area $\times$ total height) as the compulsory explanatory variable. This kind of models have shown successful results with Pinus caribaea grown in UK (Subasinghe, 1998) and Eucalyptus grandis grown in upcountry of Sri Lanka (Subasinghe, 2001). However, for this study, the better results were given by the logarithmic model and therefore it was used to predict the volume of the plantations of the selected species.

According to Burkhart (2003), the forestry sector in most tropical countries suffers due to lack of re-measured data from permanent sample plots. However, in order to minimise the 
undesirable effects of unexplained variations (i.e., to minimise the sampling error) it is essential to use data from the same trees or sample plots re-measured at intervals over a long period. In the absence of such data, modellers have no other option than to use data from temporary sample plots thereby introducing a considerable amount of error into the constructed models due to site variations and other influencing factors.

\section{CONCLUSION}

It was not possible to construct a common volume prediction models for both site types. The models given in equations 3.1 and 3.3 are the finally selected ones for site type II and I respectively. In order to identify the site variations, it is recommended to use the information given in Tables 2.1 and 3.1.

\section{ACKNOWLEDGEMENT}

The financial support of the National Science Foundation is acknowledged.

\section{REFERENCES}

Adame, A., Hynynen, J, Canellas, I. and del R1o, M. 2008. Individual-tree diameter growth model for rebollo oak (Quercus pyrenaica Willd.) coppices. Forest Ecology and Management 255:1011-1022.

Avery, T.E. and Burkhart, H.E., 1994. Forest measurements $4^{\text {th }}$ ed. McGraw Hill, New York.

Bertalanffy, Lv., 1957. Quantitative laws in metabolism and growth. Quart Rev. Biol. 32:217-231. In Rammig, A., Bebi, P. Bugmann, H and Fahse, L., 2007. Adapting a growth equation to model tree regeneration in mountain forests. European Journal of Forestry Research 126:49-57.

Boisvenue, C., Temesgen, H and Marshall, P., 2004. Selecting a small tree height growth model for mixed species stands in the southern interior of British Columbia, Canada. Forest Ecology and Management, 202: 301-312.

Burkhart, H.E., 2003. Suggestions for choosing an appropriate level for modelling forest stands. In A. Amerao, D. Reed and, P. Soares (ed) Modelling forest systems, CAB International, UK.

Fernandez, MP and Norero, A, 2006. Relation between length and diameter of Pinus radiata branches. Scandinavian Journal of Forestry Research 21: 124-129.

Fontes, L., Tome, M., Thompson, F., Yeomans, A., Luis, J.S. and Savill, P., 2003. Modelling the Douglas-fir (Pseudotsuga menziesii (Mirb) Franco) site index from site factors in Portugal. Forestry 76:491-507.

Lundqvist-Korf, 1939 In Palahi M., Tome M., Pukkala T., Trasobares A., Montero G., Site index model for Pinus sylvestris in north-east Spain, Forest Ecology and Management 187 (2004) 35-47.

Palahi M., Tome M., Pukkala T., Trasobares A., Montero G., 2004. Site index model for Pinus sylvestris in north-east Spain, Forest Ecology and Management. 187 (2004) 35-47.

Philip, M.S., 1994. Measuring trees and forests. 2nd ed. CAB International, UK.

Rammig, A., Bebi, P. Bugmann, H and Fahse, L., 2007. Adapting a growth equation to model tree regeneration in mountain forests. European Journal of Forestry Research 126:49-57.

Salas, C. and Garcia, O., 2006. Modelling height development of mature Nothofagus oblique. Forest Ecology and Management 229:1-6.

Proceedings of the $15^{\text {th }}$ International Forestry and Environment Symposium, 26-27 November 2010.

Published by Department of Forestry and Environmental Science, University of Sri Jayewardenepura, Sri Lanka. 
Sanchez-Gonzales, M., Tome, M and Montero, G., 2005. Modelling height and diameter growth of dominant cork oak in Spain. Annals of Forest Science 62: 633-643.

Schumacher, F.X., 1939. A new growth curve and its application to timber yield studies. Journal of Forestry 37:819-820.

Soares, P., Tome, M., Skovsgaard, J.P. and Vanclay, J.K., 1995. Evaluating a growth model for forest management using continuous forest inventory data. Forest Ecology and Management 71: 251-266.

Subasinghe, S.M.C.U.P., 1998. Construction of growth models for Pinus nigra var. maritime (Ait) Melville (Corsican pine) in Great Britain. PhD Thesis, School of Agricultural and Forest Sciences, University of Wales Bangor, UK.

Subasinghe, S.M.C.U.P., 2001. Construction of an individual tree volume prediction model for Eucalyptus grandis Hill ex Maiden in Sri Lanka, Research Report, University of Sri Jayewardenepura, Sri Lanka.

Vanclay, J.K., 1994. Modelling forest growth and yield: Applications to mixed tropical forests. CAB International, UK.

Wang, Y., Raulier, F. and Ung, C.H., 2005. Evaluation of spatial predictions of site index obtained by parametric and nonparametric methods-A case study of lodgepole pine productivity. Forest Ecology and Management 214:201-211 